IN REFERANCE TO UP PROPELLING-MECHANICS, CREATING

A PUSH KINETIC EQUITION AS A BASE TO CALCULATE THE MORE suitable WEIGHT REQUIRED TO UPLIFT ACERTAIN MASS FROM HALF KNEELING POSITION.

Tamer Hussein Alshetaihy

words: gravity, Newton lows, force platform.

\title{
Introduction:
}

There is no cause to suspect that the biomechanical research progress - to a large extent -depends upon the development and preparation of the appropriate measurement methods that allow the possibility of recording the kinetic variables accurately and thereby reduce the extent of error in measurements of these variables, which provide us, as much as possible, with instant and fast information about the nature of the biomechanical variables movement, under study.

The rapid and successive development in the sports field is a reflection of technical progress in all other scientific and applied fields, any evolution in the branch of science contributes one way or another in the development of physical education and sport, and this development in the levels came as a result of the use of modern scientific and technical methods in various areas of knowledge and in a practical way in the sports field, which contributed to the developing of research and studies in the fields of sports, also led to improved performance and develop training methods for the high levek of sporting achievement (ovmar Mohammed Sabri, 1984).

Mohammed Jaber Briqaa (2003), refers that it has to be the existence of integrity and unites knowledge between different systems and science, before there hasn't any sign of any progress in the understanding of human movement. (Mohammed Jaber Briqaa, 2003).

Elsaid Abdel-Maksoud also indicates (1994), noted that the modern sports training theories is not limited to the educational organization of the training process, and the special ways of organizing the training process as a unit of modules of education and building high athletic level, since it determines to a large degree through emanating from the fields of psychology, physiology and bio-mechanics information , as well as through the full use of this information as possible to be athletic training in the form of description or explanation or a technological predictions of optimal use for training of scientific information theories of information. (Elsaid Abdel-Maksoud) (1:24.25) 
Nahed Alsabbagh and Gamal Alaaddin (1999) mentioned that each activity has its own law; Deviation from that law is a mistake. so biomechanics seeks in how the individual has been promoted to the highest levels of sports, without prejudice to the legal requirements of the Organizing for sports racing involved, as well as, the biomechanics opened many doors for coaches to enter in solving the training problems through scientific research and thus increased their awareness and understanding of the profession of athletic training, such as search and technical performance of ways in various sports activities, and innovating tests to measure and evaluate renderings and motor skills for various activities, modify the format and syntax tools and the new development of the means of athletic training. (Nahid Anwar al-Sabbagh, Gamal Aladdin, 1999)

Gird Hochmoth summarizes the basic duties vital to the mechanics in the following points:

setting optimizing determinants of athletic performance mode that means bio-mechanics must know the most appropriate solutions for sports movements under consideration.

$>$ Dissemination of acquired information about the art of the perfect sports performance individually and put it in the image of firm foundations of bio mechanics to serve the art of optimal athletic performance.

$>$ Development methods of qualitative research, with respect to biomechanics in terms of speed and instant access to information on training.

continue to develop research methods for bio-mechanics. build on the foundations of the use of biomechanics in exercises aimed at developing physical abilities. (Gerd Hokhmut ,1978).

new Level sports, in the tournament sector, requires the use of the scientific method for planning and directing sports training process, which require a coach to have objectivity and effectiveness of semantics on the status of the players who worked with them until he can be planned properly training process.

Measuring the force needs for a number of times to carry the weight (weight lifting) in order to get the maximum power of a player, through which they can form loads, and that means that the measurement process requires consuming time and effort during the training process, but the used method facilitate us the speed to identify the current level for individuals to recognize the most appropriate and not maximum gravity. 
Through Which the load can be periodically formed, mindful of the lack of stress in the gravity estimation of the player, When doing a simple comparison of the two methods, we find that the traditional method to estimate the maximum weight of gravity a player can carry the player, The innovative method relies on account of optimized gravity for the player to form the training load during lifting weight on knees bent position, the traditional method needs to repeat lifting weight increasingly to estimate the gravity. in innovative method They do not need to repeat the measurement, but rely on the best recording vertical distance as the old-fashioned way to consume big time of the training program while the innovative method does not need time to get to know the weight of the most appropriate, as the traditional method need the player exert a great effort, they are performed in a place next to the wall to record the distance you know from which the weight of the most appropriate and the traditional way are once every month due to waste time and effort .while the method innovative method can calculate the gravity several times during the month without consuming time or effort, and finally the formation of the load in the traditional way is linked to the monthly testing, while the formation of the load in the innovative way linked to the status of the player daily. At the end of the presenting problem, we can identify a problem of research as being a scientific attempt to form the training load innovative manner based on the mechanical propel in the calculating gravity best suited to carry the weight from half kneeling position, unlike the traditional method, based on knowledge of the maximum weight of the player can carry. Gravity estimation.

Key words: kinetic variables, biomechanical variables, most appropriate solutions for sports movements, optimal athletic performance, training process, lack of stress, on knees bent position, the traditional way, the mechanical propel.

\section{Research importance:}

the instant feedback of information is One of the most important trends in the modern that is: For getting the athlete and coach alike - as soon as possible - of the information concerning the position of the physiological and bio-mechanical, and so forth important standards.

\section{Scientific importance:}

Setting novelty status Training foundation based on a scientific basis to save time and effort.

\section{Applied prominence:}

Training programs Modifying, in light of, the equations of motion and mechanical variables. 
Aim of the research:

The research aims to calculate the most appropriate gravity, in reference of, momentum -mechanics through:

1- Find a correlation between anthropometric variables and the player's ability to calculate the weight of the most appropriate on carry the weight of a half bend of the knees and then by checking the vertical jump distance and weight of the player.

2- setting a check sheet model by which to calculate the weight of the most appropriate setting in terms of disclosure of the vertical jump distance and weight of the player.

\section{Research definitions:}

Gravity:

Gravity of the foreign powers that have a decisive influence on the course of the movement of the body and the point of impact of the outcome of these forces and the direction of its line always have the down force is equal to body weight. (Nahid Anwar al-Sabbagh, Gamal Aladdin, 1999).

Key words: Scientific importance, applied prominence, vertical jump distance, check sheet model,

\section{Research procedures:}

The study procedures built on number of operations arranged as follows: The method used: descriptive approach was used, as the most appropriate approach to the problem of research.

The research sample:

The researcher has collected a random sample of five players in diverse weights and physical abilities of various sports. Results' Table refers to the arithmetic mean, standard deviation and coefficient of torsion of the research sample and the sample homogeneity of individuals is evident in these variables ranging sprains coefficient between $(+/-3)$.

\section{Table (1)}

Statistical data for the characterization of the players of the research sample (sample homogeneity) $\mathbf{n}=\mathbf{0}$

\begin{tabular}{|l|l|l|l|l|l|}
\hline \multicolumn{1}{|c|}{ Variables } & Unit & $\begin{array}{l}\text { Arithmetic } \\
\text { mean }\end{array}$ & Median & $\begin{array}{l}\text { standard } \\
\text { deviation }\end{array}$ & $\begin{array}{l}\text { Torsion } \\
\text { modulus }\end{array}$ \\
\hline Age & Year & 21.40 & 22.00 & 1.94 & 0.081 \\
\hline Length & $\mathrm{C} \mathrm{m}$ & 177.60 & 175.00 & 6.22 & 0.153 \\
\hline Weight & $\mathrm{Kg}$ & 67.20 & 65.00 & 11.92 & 0.288 \\
\hline Training age & Year & 6.62 & 7.00 & 1.27 & 0.393 \\
\hline
\end{tabular}




\begin{tabular}{|l|l|l|l|l|l|l|}
\hline $\begin{array}{l}\text { Chick of } \\
\text { vertical } \\
\text { jump }\end{array}$ & Attempt (1) & C m & 274.80 & 280.00 & 16.14 & 0.109 \\
\cline { 2 - 7 } & Attempt (2) & C m & 276.60 & 282.00 & 13.88 & 0,086 \\
\cline { 2 - 7 } & Attempt (3) & C m & 276.60 & 281.00 & 13.57 & 0.301 \\
\hline
\end{tabular}

Table Results refer to the arithmetic mean, standard deviation and coefficient of torsion of the research sample, and the sample homogeneity of individuals is evident, in these variables ranging sprains coefficient between $\left({ }^{+}-3\right)$.

Means and tools of data collection :-

- Alrstamitr device for measuring length;

$\neg$ Medical scales for weight measure;

$\neg$ Platform of Power measuring device;

$\neg$ Test of Vertical jump from stability;

$\neg$ Newton Mechanical laws;

$\neg$ Capacity Mechanical laws;

$\neg$ Data registration form;

$\neg$ Measuring Tape;

$\neg$ A computer, and.

$\neg$ A Printer. 
The operational procedures of the study:

It has been applied to study the biomechanics lab at the Faculty of Physical Education, University of Kafr El-Sheikh and the fact that each player of the five players (sample) to make three attempts to measure vertical jump force platform consecutive periods of rest during the adjusting force measuring device platform.

\section{Statistical treatment:}

To achieve the goal of research, the researcher used the following statistical methods:

- Arithmetic average.

-Mediator.

- Standard deviation.

- Torsion coefficient.

Scientific basis, on which the study was built 0n: -

1. The vertical movement equation of Newton:
(1) $V 2 f=V 2 i+2 g h$
(2) $\quad V^{2} i=-2 g h$

As the final velocity of vertical jump $=$ zero

Negative signal here means that the movement against gravity, and can be referred to ignore because we need the absolute value of the speed of the primary starting point $(\mathrm{Vi})$, where the vertical distance $(\mathrm{h})$ represents a registered player of the vertical distance in the vertical jump test of stability. 2-power

(3) Power $(P)=F^{*} V$

Power $=$ force $\mathrm{x}$ velocity

(3) To calculate the power force(k.g), according to Newton low, through finding the velocity from equation no (2) above $\left(\mathrm{V}^{2} \mathrm{i}=-2 \mathrm{gh}\right.$

2. calculate the appropriate weight in lifting a weight from ;kneeling position test force exerted to push the earth can be identified by the player and the distance recorded from the relationship weight (3)( (3)Power $(P)=F^{*}$ V-----------------------), this force represents the highest amount produced by the player to be launched from the ground or when the knee angle represents almost 180 degrees, therefore, in order to identify 
the amount of power that can player produced when or knee angle of 90 degrees means that this amount is divided by 2 .

\section{(4)Optimum weight $=\mathrm{P} / 2$}

The most appropriate gravity $=$ force resulting from push $/ 2$ Example: Calculate the weight appropriate to the player and weighed 80 $\mathrm{kg}$, was able to record a vertical distance of 0.6 meters answer: The force Player weight $x$ sqrt (of the weakness of gravity wheel in vertical distance) exerted in the push (the ability) $=$ $=80 \times \sqrt{2 \times 9.81 \times 0.6}=80 * 3.43=274.48 \mathrm{~kg}$ Power

Note that the speed with which was launched by the player representing $3.43 \mathrm{~m} / \mathrm{s}$

By identifying the highest amount of force exerted by the player in the propel to reach the distance recorded a full extension of the knee $274.48 \mathrm{~kg}$, while for gravity appropriate to carry the weight of half bent knees or at a 90 degree angle or in the middle of payment trip is done by dividing the amount by 2 becomes $137.24 \mathrm{~kg}$ because the 90 -degree half of the 180 degrees.

\section{Scientific evidence to prove the proper weight:}

Using a registry strength platform to get to know the amount of force exerted at the moment of launching and a moment of bending knees to a half, on a sample of five players of different weights where each of them perform three attempts on the force platform synchronized with the registration of the vertical distance will show model to demonstrate in one of the curves. And through the work of mechanical treatment as described in the previous example, we can get the following. 


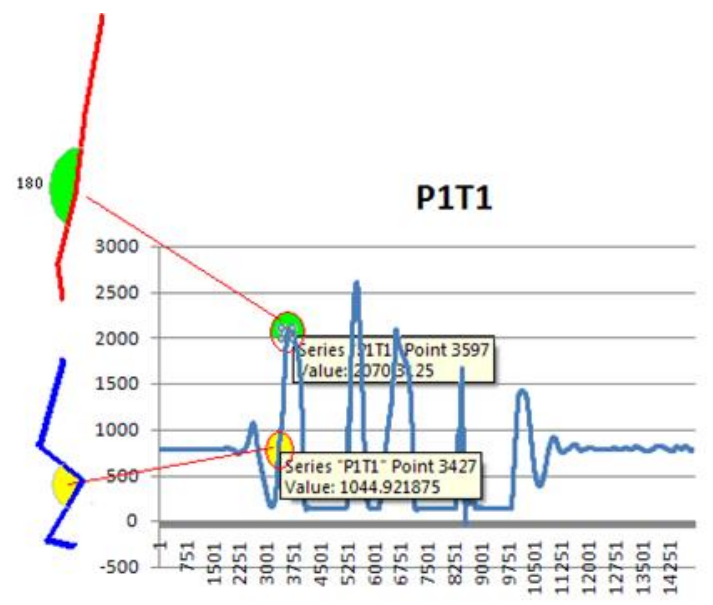

Figure 1 illustrates the sample amounts of force exerted (in newton's) during the push stage (Mode bend your knees a half - a moment of launching) - a player number (1) first attempt.

Is evident from Figure 1 that the amount of force at the moment of launching had reached (2070.31) Newton while the amount of power at the moment knees bent half have reached (1044.92) Newton, which represent almost 50\% from the moment of propel, which tells us that it calculates the momentum made the player a moment launching $(\mathrm{kg})$ weight is best suited to carry the weight of the bend knees represents almost half.

Key words: descriptive approach, sample homogeneity, Arithmetic average, Mediator, Standard deviation, Torsion coefficient. 


\section{Table (2)}

Movement variables- Synchronized. On the platform power device with a vertical jump - the three attempts of the player number (1).

\begin{tabular}{|c|c|c|c|c|c|c|c|}
\hline Player & $\begin{array}{c}\text { Force at } \\
\text { the } \\
\text { Moment } \\
\text { of } \\
\text { launching } \\
\text { (newton) }\end{array}$ & $\begin{array}{c}\text { Force at the } \\
\text { Moment of } \\
\text { half } \\
\text { Kneeling } \\
\text { (newton) }\end{array}$ & $\begin{array}{c}\text { Height } \\
\text { of start }\end{array}$ & $\begin{array}{c}\text { Force } \\
\text { Of start }\end{array}$ & $\begin{array}{c}\text { Vertical } \\
\text { Jump } \\
\text { distance }\end{array}$ & $\begin{array}{c}\text { Power } \\
\text { At the } \\
\text { moment of } \\
\text { launching }\end{array}$ & $\begin{array}{c}\text { Ratio of Force } \\
\text { at the } \\
\text { Moment of half } \\
\text { Kneeling: } \\
\text { Force at the } \\
\text { Moment of } \\
\text { launching\% }\end{array}$ \\
\hline P1t1 & 2070.31 & 1044.92 & 2.26 & 2.8 & 0.54 & 211.4 & 0.505 \\
\hline P1t2 & 2308.65 & 1177.41 & 5.15 & 2.82 & 0.67 & 235.34 & 0.50 \\
\hline P1t3 & 2246.09 & 1123.05 & 2.180 & 2.81 & 0.063 & 228.96 & 0.500 \\
\hline
\end{tabular}

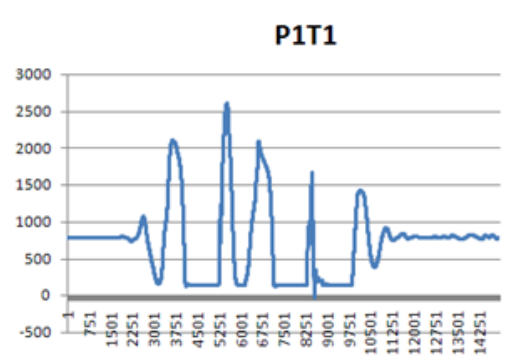

Player number (1) first trial

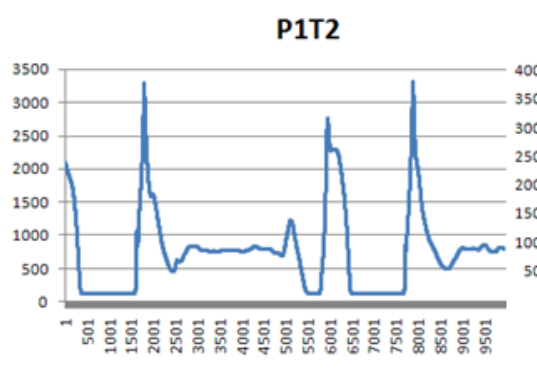

player number (1) second trial
P1T3

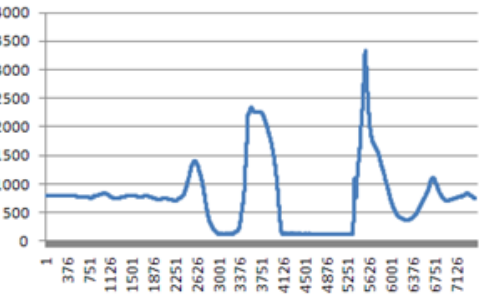

player number (1) third tria

Illustrate (2),

Force curve in the vertical jump test on a force platform player (1) in one of the three attempts

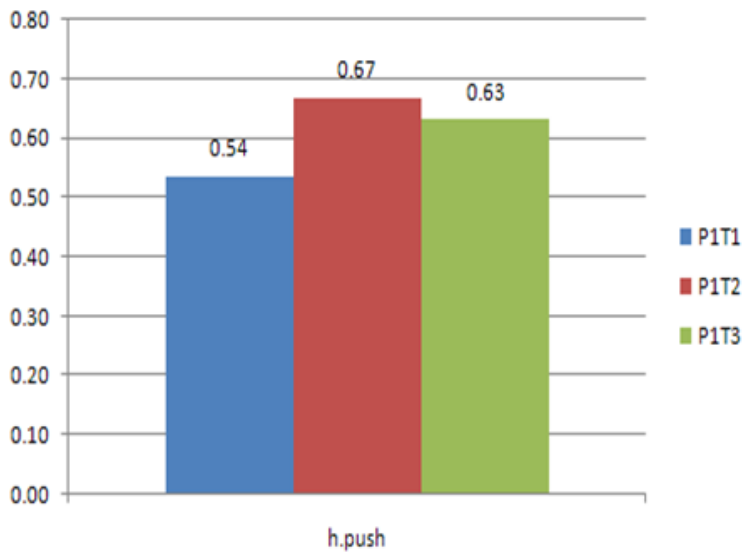

Figure 3:

Vertical jump distance of player - (one) in three attempts

It is shown in Table (2) different amounts of platform power force (2070.31) (2308.65) (2246.09) Newton led to different plyometric, as shown in Figure 3 (0.54) (0.67) (0.63) meters respectively. Consequent difference in the amount of momentum the moment of leaving the ground 
after the conversion to $\mathrm{kg}$ (211.04) (235.34) (228.96) the two legs in this position for a moment of force were in a full extension state of the knee means that the angle represent (180 degrees), and notes that the amounts of force on a platform of force at the moment of your knees bent half was (1044.92) (1177.41) (1123.05) and Newton this value represents approximately $50 \%$ of the payment amount for the moment taking off.

Table (3)

Movement variables- Synchronized. On the platform power device with a vertical jump - a player number (2) of the three attempts

\begin{tabular}{|c|c|c|c|c|c|c|c|}
\hline Player & $\begin{array}{c}\text { Force at } \\
\text { the } \\
\text { Moment } \\
\text { of } \\
\text { launching } \\
\text { (newton) }\end{array}$ & $\begin{array}{c}\text { Force at the } \\
\text { Moment of } \\
\text { half } \\
\text { Kneeling } \\
\text { (newton) }\end{array}$ & $\begin{array}{c}\text { Height } \\
\text { of start }\end{array}$ & $\begin{array}{c}\text { Force } \\
\text { Of start }\end{array}$ & $\begin{array}{c}\text { Vertical } \\
\text { Jump }\end{array}$ & $\begin{array}{c}\text { Power } \\
\text { At the } \\
\text { moment of } \\
\text { launching }\end{array}$ & $\begin{array}{c}\text { Ratio of Force } \\
\text { at the } \\
\text { Moment of } \\
\text { half } \\
\text { Kneeling: } \\
\text { Force at the } \\
\text { Moment of } \\
\text { launching\% }\end{array}$ \\
\hline P2t1 & 2011,71 & 1046,09 & 2,57 & 2,95 & 0,38 & 205,07 & 0,520 \\
\hline P2t2 & 1884,76 & 923,53 & 2,61 & 2,94 & 0,33 & 192,13 & 0,490 \\
\hline P2t3 & 1816,4 & 908,20 & 2,61 & 2,92 & 0,31 & 185,16 & 0,500 \\
\hline
\end{tabular}

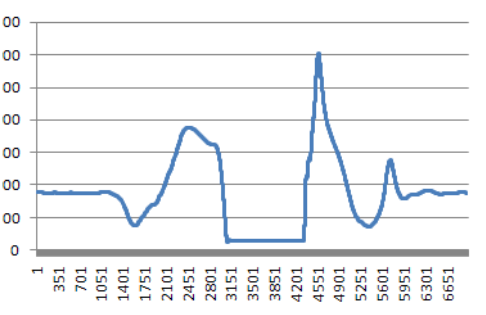

Player (2) trial (3)

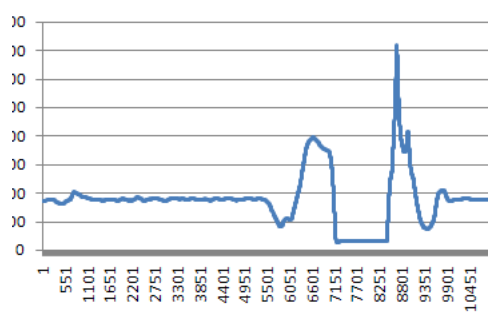

Player (2) trial (2)

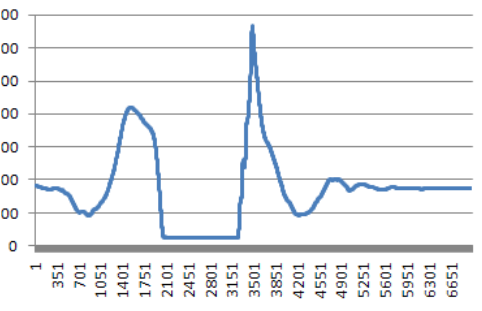

Player (2) trial (1)

\section{Form (4)}

Force curve in the vertical jump test on a force platform. The player number (two) in three attempts

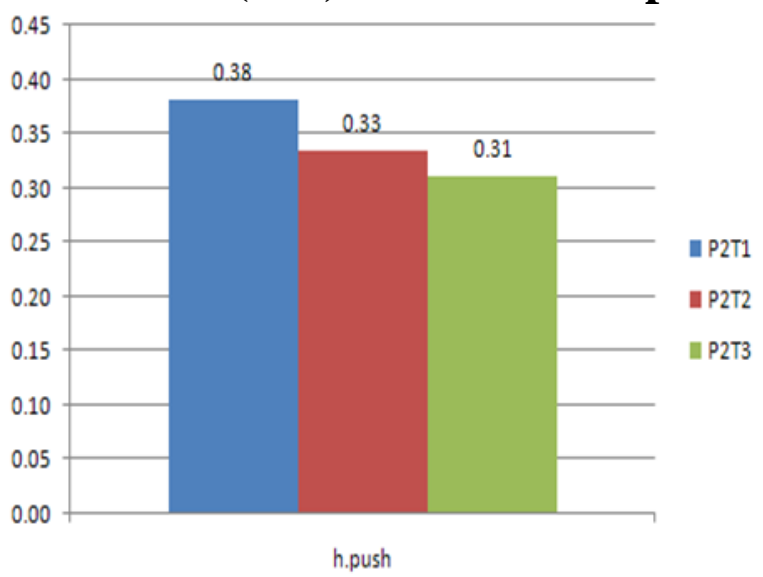

Form (5) vertical distance - player number (2), in three attempts 
Evident from the table (3) different amounts force of platform power force at the moment of launch (2011.71) (1884.76), (1816.4) Newton led to different jump distances, as shown in Figure 5 (00:38), (0:33), (0.31 meters), respectively. Consequent difference in the amount of momentum the moment of leaving the ground after the conversion to $\mathrm{kg}$ (205.07) (192.13) (185.16) as the two legs in this position for a moment of payment were in a state full extension of the knee ie the angle represent (180 degrees), and notes that the amounts of force on the force platform at the moment knees bent half was (1046.09), (923.53) (908.20) and Newton this value represents approximately $50 \%$ of the payment amount for the moment of launch.

\section{Table (4)}

Movement variables- synchronized. On the platform power device with a vertical jump - the player number (3) in three attempts

\begin{tabular}{|c|c|c|c|c|c|c|c|}
\hline Player & $\begin{array}{c}\text { Force at } \\
\text { the } \\
\text { Moment } \\
\text { of } \\
\text { launching } \\
\text { (newton) }\end{array}$ & $\begin{array}{c}\text { Force at the } \\
\text { Moment of } \\
\text { half } \\
\text { Kneeling } \\
\text { (newton) }\end{array}$ & $\begin{array}{c}\text { Height } \\
\text { of start }\end{array}$ & $\begin{array}{c}\text { Force } \\
\text { Of start }\end{array}$ & $\begin{array}{c}\text { Vertical } \\
\text { Jump }\end{array}$ & $\begin{array}{c}\text { Power } \\
\text { At the } \\
\text { moment of } \\
\text { launching }\end{array}$ & $\begin{array}{c}\text { Ratio of Force } \\
\text { at the } \\
\text { Moment of } \\
\text { half } \\
\text { Kneeling: } \\
\text { Force at the } \\
\text { Moment of } \\
\text { launching\% }\end{array}$ \\
\hline P3t1 & 1652,58 & 851,08 & 2,04 & 2,55 & 0,51 & 168,46 & 0,515 \\
\hline P3t2 & 1542,96 & 803,88 & 2,15 & 2,6 & 0,45 & 157,28 & 0,521 \\
\hline P3t3 & 1401,36 & 720,30 & 2,23 & 2,6 & 0,37 & 142,85 & 0,514 \\
\hline
\end{tabular}
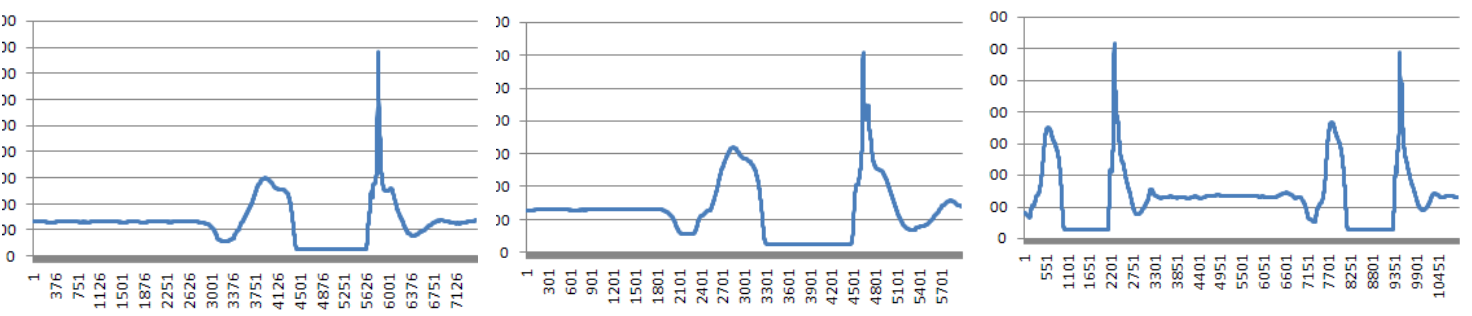

Player number(3) T(3) Player number(3) T(2) Player number(3) T(1)

Form (6)

Force curve in the vertical jump test on a force platform the player number (3) in three attempts

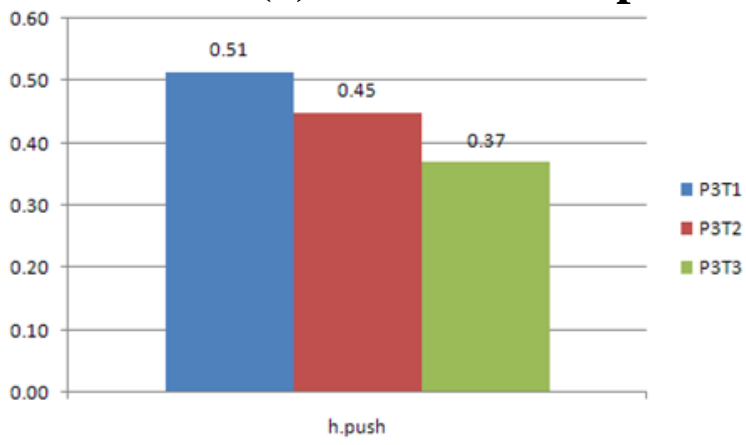

Form (7) vertical jump - player number (3) in three attempts 
It is shown in table (4) differing force amounts platform power force at the moment of launch (1652.58) (1542.96) (1401.36) Newton led to different jump distances as shown in Figure 7 (12:51), (0:45), (0.37 meters), respectively. Consequent difference in the amount of momentum the moment of leaving the ground after the conversion to $\mathrm{kg}$ (168.46) (157.28) (142.85) as the two legs in this position for a moment of force was in full extension of the knee ie the angle represent (180 degrees), and notes that the amounts of payment on a platform of force at the moment of half bent knees was (851.08) (803.88) (720.30) and Newton this value represents approximately $50 \%$ of the force amount for the moment launch.

\section{Table (5)}

Movement variables -synchronized. On the platform power device with a vertical jump - the player number (four) in three attempts

\begin{tabular}{|c|c|c|c|c|c|c|c|}
\hline Player & $\begin{array}{c}\text { Force at } \\
\text { the } \\
\text { Moment } \\
\text { of } \\
\text { launching } \\
\text { (newton) }\end{array}$ & $\begin{array}{c}\text { Force at the } \\
\text { Moment of } \\
\text { half } \\
\text { Kneeling } \\
\text { (newton) }\end{array}$ & $\begin{array}{c}\text { Height } \\
\text { of start }\end{array}$ & $\begin{array}{c}\text { Force } \\
\text { Of start }\end{array}$ & $\begin{array}{c}\text { Vertical } \\
\text { Jump }\end{array}$ & $\begin{array}{c}\text { Power } \\
\text { At the } \\
\text { moment of } \\
\text { Launching }\end{array}$ & $\begin{array}{c}\text { Ratio of Force } \\
\text { at the } \\
\text { Moment of } \\
\text { half } \\
\text { Kneeling: } \\
\text { Force at the } \\
\text { Moment of } \\
\text { launching\% }\end{array}$ \\
\hline P4t1 & 1864,23 & 947,99 & 2,11 & 2,62 & 0,51 & 190,03 & 0,523 \\
\hline P4t2 & 1858,22 & 936,54 & 2,14 & 2,65 & 0,51 & 189,42 & 0,504 \\
\hline P4t3 & 1833,51 & 933,26 & 2,16 & 2,65 & 0,49 & 186,90 & 0,509 \\
\hline
\end{tabular}

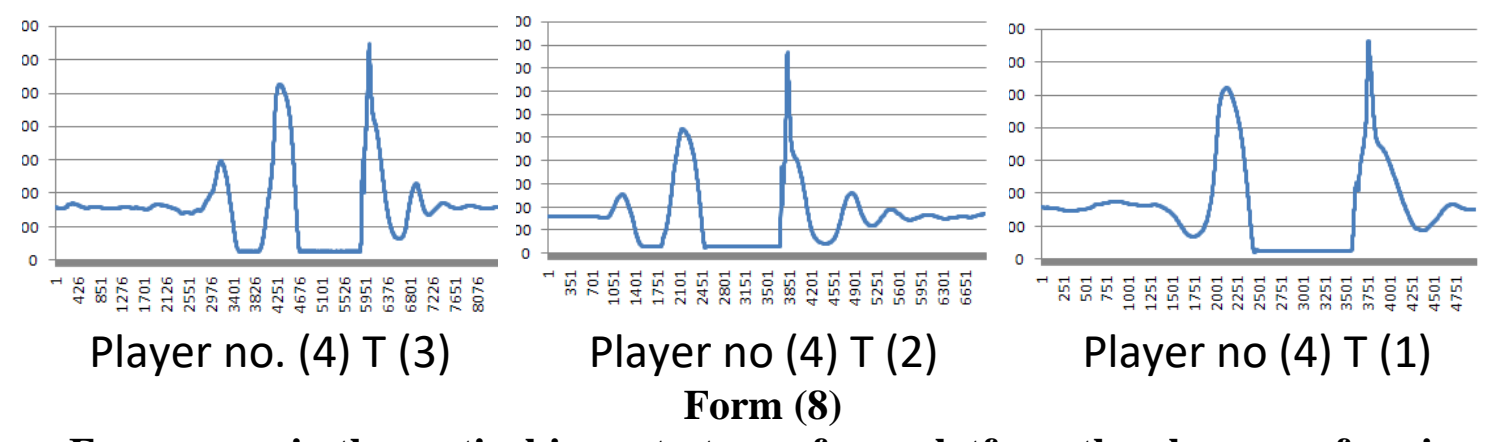

Force curve in the vertical jump test on a force platform the player no. four in (three) attempts

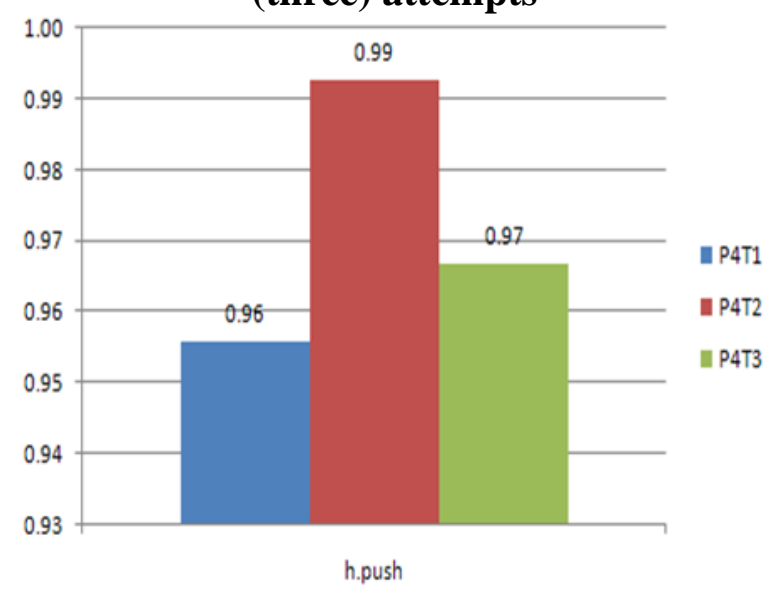

Form (9)

Vertical jump distance - player no. (4) In three attempts 
Seen from the table (5) different force amounts platform power force moment launching (1864.23) (1858.22) (1833.51) Newton led to different vertical jump distances as shown in Figure (9) (0.51) (0.51) (0.49 meters), respectively. Consequent difference in the amount of momentum the moment of leaving the ground after the conversion to $\mathrm{kg}$ (190.03) (189.42) (186.90) as the two legs in this position for a moment of payment was in full extension of the knee ie the angle represent (180 degrees), and notes that the amounts of force on the force platform at the moment knees bent half was (974.99) (936.54) (933.26) and Newton this value represents approximately $50 \%$ of the force amount for the moment launching.

Table (6)

Movement variables -synchronized. On the platform power device with a vertical jump - the player no. (5) in three attempts

\begin{tabular}{|c|c|c|c|c|c|c|c|}
\hline Player & $\begin{array}{c}\text { Force at } \\
\text { the } \\
\text { Moment } \\
\text { of } \\
\text { launching } \\
\text { (newton) }\end{array}$ & $\begin{array}{c}\text { Force at the } \\
\text { Moment of } \\
\text { half } \\
\text { Kneeling } \\
\text { (newton) }\end{array}$ & $\begin{array}{c}\text { Height } \\
\text { of start }\end{array}$ & $\begin{array}{c}\text { Force } \\
\text { Of start }\end{array}$ & $\begin{array}{c}\text { Vertical } \\
\text { Jump }\end{array}$ & $\begin{array}{c}\text { Power } \\
\text { At the } \\
\text { moment of } \\
\text { launching }\end{array}$ & $\begin{array}{c}\text { Ratio of Force } \\
\text { at the } \\
\text { Moment of } \\
\text { half } \\
\text { Kneeling: } \\
\text { Force at the } \\
\text { Moment of } \\
\text { launching\% }\end{array}$ \\
\hline P5t1 & 2192,38 & 1135,65 & 2,45 & 2,82 & 0,37 & 223,48 & 0,518 \\
\hline P5t2 & 2036,13 & 1026,21 & 2,50 & 2,82 & 0,32 & 297,56 & 0,504 \\
\hline P5t3 & 1904,29 & 948,34 & 2,57 & 2,85 & 0,28 & 194,12 & 0,498 \\
\hline
\end{tabular}

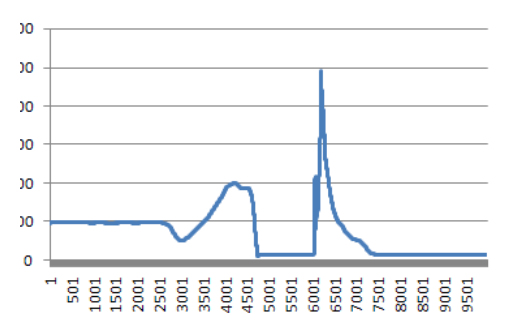

Player no 5 T 3

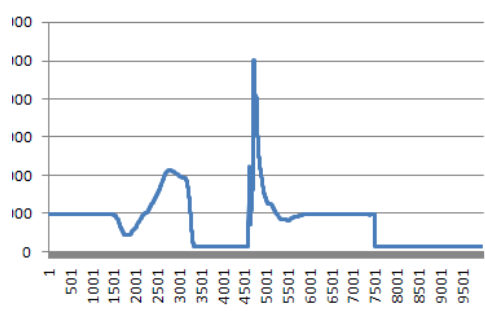

Player no 5 T 2

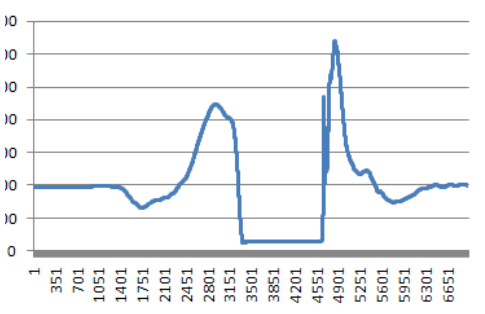

Player no 5 T 1

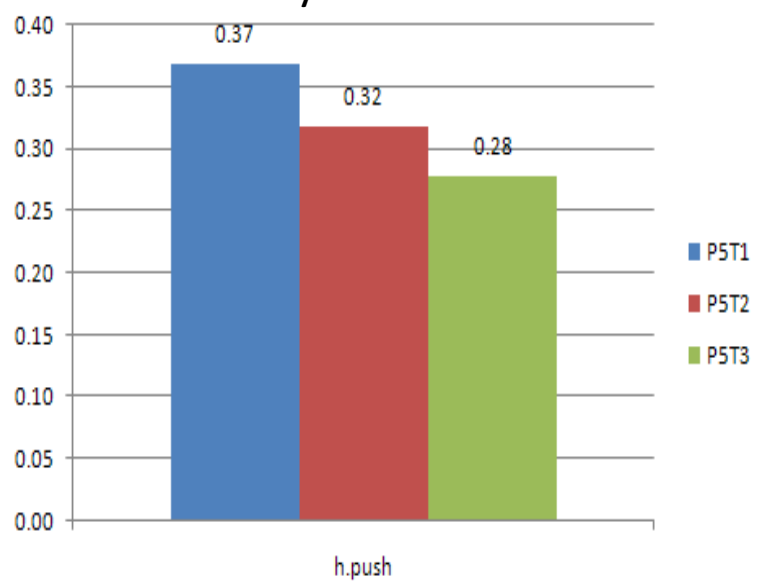

Form (11) Vertical jump distance - player no (5) in three attempts 
seen from the table (6) different amounts force.2192.38,2036.13,1904.29 Newton, at the moment of launching led to different vertical jump as shown in Figure (11) (0.37) (0.32) (0.28 meters), respectively. Consequent difference in the amount of momentum the moment of leaving the ground after the conversion to $\mathrm{kg}(223.48)$ (207.56) (194.12) and the two gegs in this position for a moment of payment was in full extension of the knee ie the angle represent (180 degrees), and notes that the amounts of force on the force platform at the moment knees bent half was (1135.65) (1026.21) (1904.29) and Newton this value represents approximately $50 \%$ of the force amount for the moment of launching.

For the most appropriate gravity and Genuinely, it is noticed although differences, initially higher and higher force is the top choice to start rising, and the highest increase for force and that the player's limits.

Calculating the appropriate weight to sample's members the according to, the player limits in terms of weight and distance of vertical jump.

Example (Player 1): Data weight $=65 \mathrm{~kg}$, the top high to start $=2.26$ meters, the highest elevation of propel $=2.82$ meters.

Dealings;

- Vertical jump distance $=2.82-2.26=0.56$ meters

- Vertical Speed $=\operatorname{sqrt}(2 \times 9.81 \times 0.56)=3.31 \mathrm{~m} / \mathrm{s}$

- momentum (the ability) $=$ weight $\times$ velocity $=65 \times 3.31=215.45$

Kgm.m / s

- gravity appropriate to carry the weight of knees bent mode $=215.45 \div$ $2=107.72 \mathrm{~kg}$

And so, for the rest of the respondents as appear in the following table. Seen from the table (7) that there is a direct correlation between vertical jump and the more appropriate weight to carry the weight from the knees bend position, the more the player achieves higher vertical jump, the more he 'll be able to carry greater weight. 
Table (7) the appropriate weight Carry the load of knees bent mode, in terms of, weight and distance jump - to the members of the research sample.

\begin{tabular}{|c|c|c|c|c|c|c|c|}
\hline Player & Weight & $\begin{array}{c}\text { Top } \\
\text { starting } \\
\text { Height }\end{array}$ & $\begin{array}{c}\text { Top } \\
\text { momentum } \\
\text { Height }\end{array}$ & $\begin{array}{c}\text { Vertical } \\
\text { jump }\end{array}$ & $\begin{array}{c}\text { Vertical } \\
\text { Velocity }\end{array}$ & Power & $\begin{array}{c}\text { Appropriate } \\
\text { weight }\end{array}$ \\
\hline 1 & 65 & 2.26 & 2,28 & 0,56 & 3,31 & 215,46 & 108 \\
\hline 2 & 75 & 2.61 & 2,95 & 0,34 & 2,58 & 193,71 & 97 \\
\hline 3 & 53 & 2.23 & 2,60 & 0,37 & 2,69 & 142,80 & 71 \\
\hline 4 & 60 & 2.16 & 2,65 & 0,49 & 3,10 & 186,04 & 93 \\
\hline 5 & 83 & 2.57 & 2,82 & 0,25 & 2,21 & 183,82 & 92 \\
\hline
\end{tabular}

it is noticed from the table (7) that there is a direct correlation between vertical jump distance and appropriate weight to carry the weight of the bend - knees position whenever any increased in vertical jump whenever the player is able to carry greater weight.

Table (8)

Check sheet to estimate the most appropriate gravity, in terms of, vertical jump test and the weight of the player. Weight $(60-69 \mathrm{~kg})$ and the distance of the jump ( 0.30 - 0.90 meters)

\begin{tabular}{|c|c|c|c|c|c|c|c|c|c|c|}
\hline $\begin{array}{l}\text { player's } \\
\text { weigh }\end{array}$ & 60 & 61 & 62 & 63 & 64 & 65 & 66 & 67 & 68 & 69 \\
\hline .030 & 73 & 74 & 75 & 76 & 78 & 79 & 80 & 81 & 82 & 84 \\
\hline 0.35 & 79 & 80 & 81 & 82 & 84 & 85 & 86 & 87 & 88 & 90 \\
\hline 0.40 & 84 & 85 & 86 & 87 & 88 & 89 & 90 & 91 & 92 & 93 \\
\hline 0.45 & 89 & 91 & 92 & 94 & 95 & 96 & 98 & 100 & 101 & 103 \\
\hline 0.50 & 94 & 96 & 97 & 99 & 100 & 102 & 103 & 105 & 106 & 108 \\
\hline 0.55 & 99 & 100 & 102 & 103 & 105 & 107 & 108 & 110 & 112 & 113 \\
\hline 0.60 & 103 & 105 & 106 & 108 & 110 & 112 & 113 & 115 & 117 & 118 \\
\hline 0.65 & 107 & 109 & 111 & 112 & 114 & 116 & 118 & 120 & 121 & 123 \\
\hline 0.70 & 111 & 113 & 115 & 117 & 119 & 120 & 122 & 124 & 126 & 128 \\
\hline 0.75 & 115 & 117 & 119 & 121 & 123 & 125 & 127 & 129 & 130 & 123 \\
\hline 0.80 & 119 & 121 & 123 & 125 & 127 & 129 & 131 & 133 & 135 & 135 \\
\hline 0.85 & 123 & 125 & 127 & 129 & 131 & 133 & 135 & 137 & 139 & 141 \\
\hline 0.90 & 126 & 128 & 130 & 132 & 134 & 137 & 139 & 141 & 143 & 145 \\
\hline
\end{tabular}




\section{FINDINGS:}

- $\quad$ access to the following mathematical relationship: the force exerted in the momentum (the ability) $=$ sqrt player $\times$ weight (of the double of gravity $\times$ vertical distance)

- Access to the dialectical relationship that the direct detection of gravity is the most appropriate in terms of the jump distance and weight of the player.

- That the force exerted on the force measuring platform at the moment of knees half bent represents almost $50 \%$ of the force exerted in the power to measure the force platform for the moment launching.

- Mechanical law for momentum within which to dispense with a way of measuring (measuring the force platform) in some physical tests, including the study list (the ability in the vertical jump).

\section{Recommendations:}

$\neg$ Use the outputs of the strength's device platform measures to deal with other processors in various physical tests that rely on the strength and power.

$\neg$ Use the check sheet to facilitate the mission of the coaches and to identify the most appropriate gravity periodically at frequent intervals during the training program.

$\neg$ it is necessity having more than one table includes a large sector of private weights players, to be taken into account the great disparity in weights which starts from $35 \mathrm{~kg}$ to $120 \mathrm{~kg}$ and more so that it serves as a reference for most of the players in different sports as well as the vertical distance table comprise between $20 \mathrm{~cm}$ to $90 \mathrm{~cm}$ in sync with players' weights within the table. 


\section{References:}

1. El saeed Abdel Maksoud: the basic aspects of training process, Elhasnaa bookshop, Cairo, Shoubra, 1994.

2. 2. Gerd Hokhmut: biomechanics and methods of scientific research for the sports movements, translated by Kamal Abdul Hamid, Dar Elmaarif, 1978.

3. Sawsan Abdel Moneim ,Essam Mohammed Amin Helmy, Mohammed Sabri Omar,Mohammed Abdul Salam Ragheb: biomechaics in the sports field, the first part, , Dar Elmaarif Egypt, 1977.

4. Sawsan Mohammed Abdel-Moneim: Demo truthfulness of the sports measuring to promote sports activities, research published, Journal of Studies and Research, Helwan University, Volume II, second edition, December 1979.

5. Talha Hossam El Din,Wafa Salahuddin,Mustafa Kamel Hamad,Said Abdul Rashid: Applied kinsiology, Part I, the first edition, the book publishing center .1998.

6. Adel Abdalbesar Ali: biomechanics, analytical assessment and measurement in physical performance, the Egyptian library for printing and publishing 2007 .

7. Louay Ghanem Sumaidie: biomechanics and sports, Mosul University, 1987.

8. Mohammad Hassan Allawi, Mohammed Nasreddin Radwan: motor performance tests - Dar Elfekr Arabi , Cairo, 1994.

9. Mohammed Jaber Briqaa, Khairia Ibrahim Elsoukary: the basic principles of bio-mechanics in the field of sports, Part I, Monshaat Elmaaref, Alexandria, 2002.

10. Mohammed Jaber Briqaa: biomechanics, Study Memoranda Faculty of Physical Education, Tanta University, 2003.

11.Mohammed Sabri Omar: the use of computers in the study and development of motor performance in the sport of rowing, the fifth scientific conference for Studies and Research of Physical Education, April 1984.

12.Nahid Anwar Elsabagh ,Jamal Aladdin: Kinesiology, Faculty of Physical Education, Alexandria, 1999. 